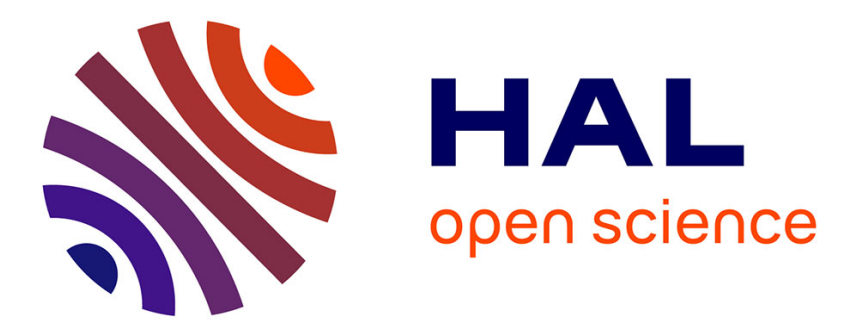

\title{
Positive effects of the Greek economic crisis on livestock farmer behaviour
}

Christos Karelakis, Zafeiris Abas, Konstantinos Galanopoulos, Konstantinos Polymeros

\section{- To cite this version:}

Christos Karelakis, Zafeiris Abas, Konstantinos Galanopoulos, Konstantinos Polymeros. Positive effects of the Greek economic crisis on livestock farmer behaviour. Agronomy for Sustainable Development, 2013, 33 (3), pp.445-456. 10.1007/s13593-013-0136-y · hal-01201387

\section{HAL Id: hal-01201387 \\ https://hal.science/hal-01201387}

Submitted on 17 Sep 2015

HAL is a multi-disciplinary open access archive for the deposit and dissemination of scientific research documents, whether they are published or not. The documents may come from teaching and research institutions in France or abroad, or from public or private research centers.
L'archive ouverte pluridisciplinaire HAL, est destinée au dépôt et à la diffusion de documents scientifiques de niveau recherche, publiés ou non, émanant des établissements d'enseignement et de recherche français ou étrangers, des laboratoires publics ou privés. 


\title{
Positive effects of the Greek economic crisis on livestock farmer behaviour
}

\author{
Christos Karelakis • Zafeiris Abas • \\ Konstantinos Galanopoulos • Konstantinos Polymeros
}

Accepted: 1 February 2013 / Published online: 27 February 2013

(C) INRA and Springer-Verlag France 2013

\begin{abstract}
The repercussions of the economic crisis have been severe upon the foundations of the Greek economy and society, and the margins for future development are more than ever strict and urgent. Within an economically turbulent period, agriculture's role is reexamined and is called to play an enhanced role, particularly the livestock sector that comprises a key growth element for the economy, bearing in mind the number of people and industries employed in the production and processing of dairy products. The present study is a classification approach regarding small ruminant farmers (sheep and goat), examining their reaction strategies against the economic crisis and its economic consequences to their farming systems. Primary quantitative data were collected through administrative (structured questionnaire) personal interviews from 110 small ruminant farmers, in the remote region of Anatoliki Macedonia and Thraki. A combination of exploratory and confirmatory factor analysis, cluster and discriminant analysis was employed to identify potentially distinct groups among the farmers. Results accrued reveal three clusters of farmers: the active entrepreneurs ( $47.2 \%$ of the sample) who adopted more dynamic and cost-effective management practices, the complacent farmers (38.1\% of the sample) who followed a passive path of management decisions and the non-active farmers ( $14.7 \%$ of the sample) who incorporate a static behaviour in the struggle against the economic crisis. The study is a first attempt to measure response to an ongoing economic crisis that has changed normal behaviour and expectations, and
\end{abstract}

C. Karelakis $(\bowtie) \cdot Z$. Abas $\cdot$ K. Galanopoulos

Department of Agricultural Development,

Democritus University of Thrace, Pantazidou 193,

68200 Orestiada, Greece

e-mail: chkarel@agro.duth.gr

K. Polymeros

Department of Ichthyology and Aquatic Environment,

University of Thessaly, Fytoko Str,

Volos 38446, Greece increased risk and uncertainty. In this sense, it demonstrates (with the use of the appropriate methodologies) the adaptation practices implemented by farmers from a significant economic sector (small ruminants), in a remote and less favourite Greek region, in order to persist and effectually respond to the current economic downturn.

Keywords Economic crisis · Small ruminant farmers · Adaptation practices $\cdot$ Cluster analysis

\section{Introduction}

5The Greek economy has been in recession since 2008 with severe economic and societal consequences. In 2011, the real gross domestic product shrinked by $7.1 \%$ compared to 2010 , mainly due to very weak domestic demand, in turn the result of fiscal adjustment, declines in household disposable income in a weak labour market and restrictive credit conditions. Productivity growth is far below eurozone average, unemployment remains high and competitiveness of the economy is weak. As regards the agricultural sector, the economic crisis triggered a drop in the farmers' income by $13.5 \%$, a rise in production cost, especially for animal farming, and a sharp decrease in the employment contribution of agriculture, although the Greek share (11.7\% in 2010) is still much higher than the corresponding EU average (4.7\%) (National Statistical Service Of Greece 2012). Nevertheless, an exit from this unstable economic path lies on the front, since the increase in unemployment in the industry and services sector seems to have affected agricultural employment as it absorbs many people who return back to rural areas and agriculture. It is worth mentioning that before the end of January 2012, 3,092 applications for land were submitted, and $35 \%$ came from unemployed people, while only $8 \%$ concerned active farmers, illustrating that in the current global turbulent period, agriculture's role is reexamined and is called to play an enhanced role. 
In this volatile economic environment, the prospects for viability and development of the livestock production systems reflect the means by which livestock farms are capable to adapt to the market volatility and evolve under uncertainty that primarily includes intense price fluctuations and future policy schemes (Darnhofer et al. 2010). Although the literature on the level of adaptation and evolvement that the farming systems exhibit under conditions of intensive uncertainty are abundant, insights on livestock farms in particular are scarce. Scholars argue that adaptation differs depending on various farm types and regional characteristics along with the economic, political and institutional conditions (Reidsma et al. 2010). The adaptation may be formed on the grounds of managerial, technical and financial features, implemented at different levels (local, regional and national), while involving different kinds of stakeholders (farmers, industries and the state) (Dedieu 2009). Smit and Skinner (2002) discriminated four main adaptation options for livestock farmers: the practices of livestock production, the farm management tactics, the technological innovations and the support on behalf of national policies and programmes. Nevertheless, several studies and literature reviews have examined the means by which farmers incorporate risk in their management of livestock farms and decision making (Hardaker et al. 1998).

The livestock sector and in particular the sheep and goat sector comprise a key growth factor for the Greek economy, within a period of economic recession, regarding the number of people and industries that are employed in production and processing activities of dairy products (Fig. 1). Livestock production, even though it remains relatively stable in the recent years, confronts certain impediments, which are related mainly to the sharp increase in input cost and the price stagnation of livestock products in the market. The economic crisis has increased the degree of uncertainty inherent in livestock farming, where the sector follows a declining course, displaying a $30 \%$ contribution in the value of agricultural production, when this percentage rises to over $50 \%$ at most European countries (Germany, Denmark and the Netherlands exhibit around $70 \%$ ). Yet, the importance of the sheep and goat sector is indispensable, since Greece is the largest European producer of sheep milk (686.000 tonnes, $24 \%$ of the European supplies in 2009) and has the largest goat herd (4.8 million heads, $37 \%$ of European total in 2009), whereas $23 \%$ of sheep milk and $62 \%$ of goat milk are processed on the farm (de Rancourt et al. 2006). However, the number of animals and production seems in slight decline (Fig. 2) (both for meat and dairy products), and there is a trend of concentration into fewer and bigger farms. Thus, it is important to examine how small ruminant farmers could survive in this economic recession and which management strategies are required to lessen or even diminish the negative consequences of the crisis.

Against this background, the present empirical effort endeavours to investigate how the small ruminant farmers (sheep and goat) have reacted against the economic crisis. The objective is to classify small ruminant farmers, from a remote and less favoured Greek region, on the basis of certain practices that have persisted during the economic recession and improved their performance. The research enquiry starts with the theoretical premises underpinning the management tactics implemented in a context of economic decline, along with the current situation of the livestock sector in Greece. Subsequently, the research methods employed to achieve the study's objective are presented, followed by the results, the discussion and some concluding remarks.
Fig. 1 Livestock practices in Greece during the economic crisis

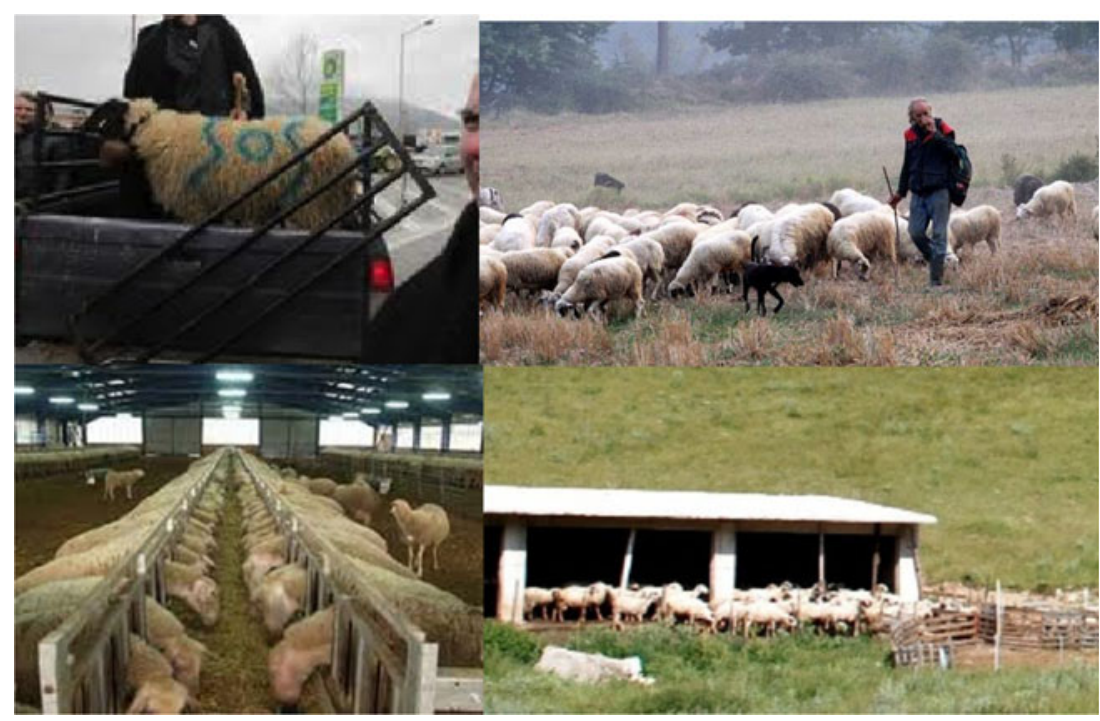



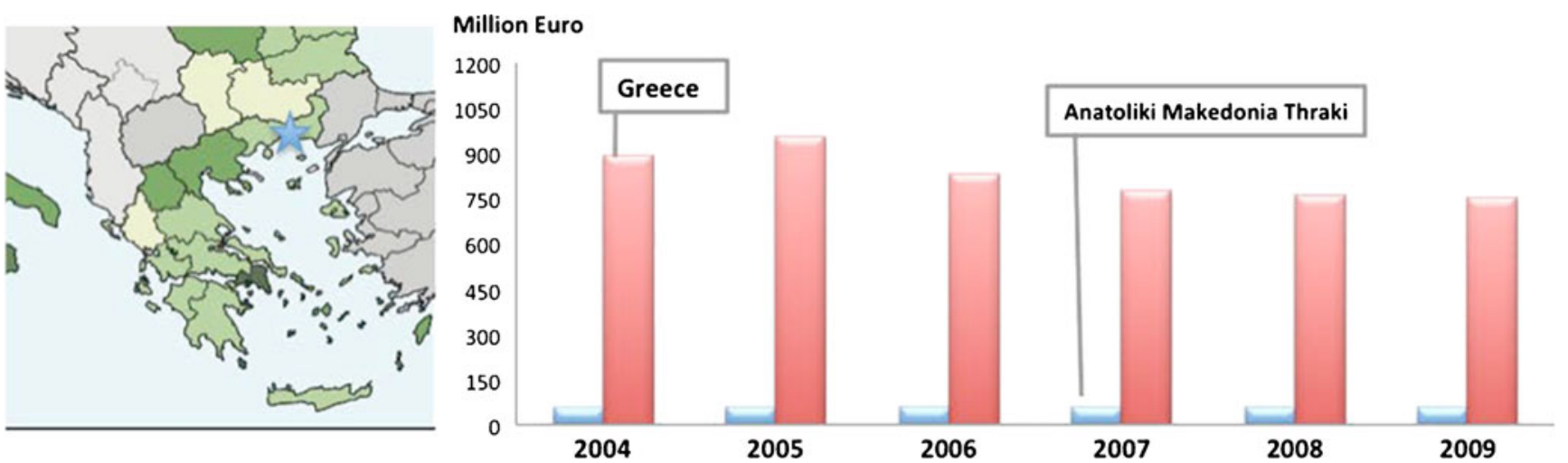

Fig. 2 Evolution of the production value (at basic price) for sheep and goats in Greece and the region of Anatoliki Makedonia and Thraki

\section{Materials and methods}

\subsection{Theoretical background}

The economic downturn is defined on the grounds of macroeconomic recession (fall in the gross domestic product) as well as in terms of environmental bombshells including a decrease in the fortunes of particular industries (Kitching et al. 2009). According to Schumpeter (1976), the impacts of an economic crisis must be evaluated at the macro-level, since an economic recession unfolds through decades or centuries, whilst insufficiencies and reduction in all the weakened sectors have an enduring effect in the economy for the years to come. Negative impacts like high unemployment, falling incomes, reduced economic activity and decreased private capital investments will be long lived, whereas the high rate of business failure can severely affect the performance of individual firms, industries and economic sectors (Koo 2009). This has provided the key scientific background for the international literature to investigate the means by which firms survive the economic stress.

An economic crisis impacts countries, regions, industries and firms unevenly, and hence, there is not a single "recession impact" for firms, nor any particular optimal way to adapt to recession conditions applicable to all firms. Generally, their response involves the adjustment of their corporate behaviour engaging in information research about macroeconomic environments and industries' conditions in order to uncover opportunities and threats (Pearce and Michael 2006). Firms are likely to retrench to mitigate financial losses, developing strategies that involve reducing costs, cutting production, reducing investment, working more with equity capital, improving efficiency and restructuring debt (Zehir 2005).

In the context of the agribusiness sector, the international literature has emphasized farmers' implemented strategies to alleviate the adverse economic impacts.
Particularly in the case of farmers, managerial skills actually prevail over other production factors so as to adapt to the new economic conditions. An efficient adaptation strategy that has been cited extensively is diversification, aiming to increase the total productivity in terms of quality, quantity and monetary value under specific, diverse agroeconomic conditions (Windle and Rolfe 2005). However, the adaptive capacity of a farm can be enhanced through strategies that involve learning through experimenting and monitoring the production outcome, ensuring farm flexibility to increase the options for new activities by the farmer and diversifying to manoeuvre and spread the risk so as to identify transition options for economic viability (Darnhofer et al. 2010).

In the livestock sector, the impacts of the economic recession are more obvious since profit margins are firmer. Subsequently, livestock farmers are more oriented to adaptation that involves new technologies in production that simplify labour and automate the milking process, reduction in animals so that only the most productive ones remain, organic farming and establishment of producer cooperatives to decrease functional costs, labour redistribution and seasonal workers, optimal use of pesticides, better pasture management, irrigation and animal waste, increase in production per animal and in the number of farm animals and improve the quality of milk production or derivatives (McNally 2001; Galanopoulos et al. 2006, 2012).

In the same manner, adopting competitive strategies seems to be a key prerequisite for the viable growth of the livestock sector in the Greek economy. The specific sector holds an important position in the economy, since almost one third of the Greek agricultural labour force is employed in the sector, employing more than 380,000 families (the processing industry related to the livestock sector employs more than 60,000 people) and contributing by $2.6 \%$ to the national gross domestic product (National Statistical Service of Greece 2012). Traditionally, it has been a dynamic agricultural sector in Greece, contributing by $18 \%$ in total 
agricultural income and representing approximately $45 \%$ of the gross value of animal production and $16 \%$ of the gross value of crop production. Dairy sheep (eight million) and goats (5.6 million) are considered as the most significant livestock sector in Greece, and the country is regarded as a European leader in sheep and goat flocks although Greek livestock farms are mainly mixed (de Rancourt et al. 2006). The majority of sheep and goat farms are small, extensive family farms, characterized by a high degree of diversification in terms of herd size, invested capital, productivity and orientation.

In the current turbulent economic environment, the sector's competitiveness may be enhanced by decreasing the production cost and generating demand for livestock products through innovative methods of qualitative production, promotion, marketing and certification (Sintori et al. 2009). Nevertheless, the extensive form of production with simple shelters and poor constructions does not improve competitiveness but imposes additional obstacles to Greek farmers. Apart from the need for synchronizing the livestock establishments, the sector confronts serious impediments that include: the lack of licenses for livestock farms with negative impacts on the absorption of national and European funds, the complexity of national laws that imposes on farmers a battery of needless actions inhibiting their businesses, the high level of bureaucracy, the lack of an electronic registration system for farms, the high prices of animal feed that actually double each year resulting in additional weight for each farmer, the degraded grazing lands and the increased debts due to bank loans that deteriorate the economic viability of farmers (Hellenic Ministry of Rural Development and Food 2011). The current economic recession along with the aforementioned problems and the sharp increase in input cost that reached almost $100 \%$ in 2008 offer a negative feature to the livestock sector, during the past 3 years, which is the decrease in production for most its products. In particular, small ruminant farmers are incapable of coping with their obligations, since the production cost has risen significantly, the retail prices did not follow that increase but, more importantly, these upturns did not reach the producers. In addition, liquidity and nonpayment risks have also been increased due to the prevailed financial risk that has been associated with variations in interest rates (Nozieres et al. 2011).

\subsection{Survey design}

\subsubsection{Case study area}

The region of Anatoliki Makedonia and Thraki comprises the eastern part of Greek Macedonia along with Greek Thrace. It is divided into the prefectures of Drama, Kavala,
Xanthi, Rodopi and Evros, including the islands of Thassos (Kavala) and Samothraki (Evros). The region comprises a remote and disadvantageous Greek region offering favourable conditions for sheep and goat farming. In 2011, the total numbers of sheep and goat farmers were 3,394 farmers and 1,037,984 sheep and goats, whereas the census population in the prefectures of Evros and Rodopi accounted for 1,650 farmers and 907,450 sheep and goats. In Greece, the number adds up to 55,406 farmers breeding approximately 13.6 million sheep and goats (National Statistical Service of Greece 2012).

\subsubsection{Data collection}

In order to meet the objective of the study, primary quantitative data were collected through a survey (structured questionnaire) with small ruminant farmers (sheep and goat) in the prefectures of Evros and Rodopi. Reviewing the extant literature, it was feasible to develop the questionnaire so as to obtain reliable measures for all the questions included (Galanopoulos et al. 2012; Nozieres et al. 2011; Ho et al. 2010; Posner et al. 2008; Rahelizatovo and Gillespie 2004; McNally 2001). The survey instrument was pre-tested through personal interviews with farmers, to ensure readability, and questions were adjusted when necessary. Simple random sampling was employed as a sampling method, because it requires relatively less knowledge about the population compared to other sampling methods (Hair et al. 2010). Accordingly, a pre-sampling procedure was conducted in a small sample of ten sheep and goat farmers in those two prefectures. The final sample was determined by the percentages of farmers' answers to the question "Have you adopted/or not a management strategy in order to confront the economic crisis?" and it was calculated from the following equations (Freedman et al. 2007):

Sample size-infinite population (where the population is greater than 50,000)

$\mathrm{SS}=\frac{\mathrm{Z}^{2} \times(\mathrm{P}) \times(1-\mathrm{p})}{\mathrm{C}^{2}}$

where

SS sample size-infinite population (where the population is greater than 50,000 )

$Z \quad Z$ value (e.g. 1.96 for a $95 \%$ confidence level), representing the probability that a sample will fall within a certain distribution

$P \quad$ percentage of population picking a choice, expressed as a decimal

$C$ confidence interval, expressed as a decimal (e.g. $0.04= \pm 4$ percentage points)

$Z \quad$ values (cumulative normal probability table) 
Data obtained from the above equation were used to calculate the final sample, employing the following equation:

New SS $=\frac{\text { SS }}{\left(1+\left(\frac{\text { SS-1 }}{\text { Pop }}\right)\right)}$

where SS is the sample size obtained from Eq. (1), and Pop is the total population.

Accordingly, the sample size for the intent and purposes of the study was $110(n=110)$, a sample significant enough and representative for the statistical analysis performed, bearing in mind also that sheep and goat farmers often appear reluctant to answer straightforward questions about their goals and preferences (Sintori et al. 2009).

All farmers registered in the catalogues of the Hellenic Milk Organization (ELOG) were randomly contacted by telephone to verify his/her availability to participate in the study. Subsequently, 110 small ruminant farmers expressed their willingness to participate in our research, and the interviews took place during the winter of 2011/2012. The farms were located in the prefecture of Evros (72 farms) and the prefecture of Rodopi (38 farms). The majority of the small ruminant farmers (Table 1) operate their systems for more than 16 years, with the majority of them having an annual income of less than 20,000 euros that stems from livestock activities in a percentage of more than $60 \%$, and possess less than 150 sheep and goats (small-sized farms). They operate mainly family farms (67\%), employing though a significant percentage (39\%) of off-farm employees, whereas half of the farmers have an additional work besides livestock.

The eight-page questionnaire was organized into three sections. The first section included general demographic information about farmers, whereas the second referred to key characteristics of the farmers and their farms. In the third section, farmers were first asked to indicate, on a fivepoint Likert scale ranging from "not at all important" to "very important," the degree of importance they attach to a battery of objectives regarding their farm. Likert scales are a non-comparative scaling technique and are unidimensional (only measure a single trait) in nature. Respondents are asked to indicate their level of agreement or disagreement on a symmetric agree-disagree scale for a series of statements; the range captures the intensity of their feelings for a given item (Burns and Burns 2008). On a second step, in order to solicit farmers' opinions regarding their farms' most effective management tactics in livestock, crop and financial management, we added four questions where respondents were asked on a five-point Likert scale which operations were mostly affected by the economic crisis and the degree to which they adopt certain management tactics to reduce the negative impacts. These practices involved general management tactics and cost reduction practices. Finally, small ruminant farmers were asked, on a five-point Likert scale, the degree of knowledge, education or training they desired to receive as concerns an array of herd management practices.

\subsection{Analysis}

The variables included in the present analysis referred to the operations mostly affected by the economic crisis, the implemented management practices (general, cost reduction and herd management) along with the knowledge, education or training small ruminant farmers desired to obtain regarding herd management practices. The methodological procedure involved three main steps. First, the validity and reliability of the variables included in the questionnaire were assessed through the implementation of exploratory factor analysis (EFA) and confirmatory factor analysis (CFA). Then the resulted factors were input in cluster analysis in order to classify farmers on the basis of the implemented management practices and the desired knowledge on an array of herd management practices. The third step of the methodology comprised the validation of the obtained farmers' clusters through the implementation of discriminant analysis.

Accordingly, the first step was to assess validity and reliability issues for the used variables through the application of statistical tests of exploratory factor analysis using the principal components extraction method (varimax rotation) and Cronbach's alpha. For the former, the principal components analysis identified ten factors that were selected using an eigenvalue of one or greater as the criterion along with the scree test. As for the latter, none of the items in the ten factors were eliminated, as they exhibited acceptable levels of reliability with alpha values exceeding 0.60 (Hair et al. 2010). The conceptual interpretation of the factor solution was enabled due to the high individual loadings on each factor. The specific factors involved the operations mostly affected by the economic crisis (CR1 - crisis and production cost and CR2 - crisis and marketing cost), management and cost reduction practices (MP1-employment cost decrease, COST1 - input cost decrease, COST2 - feed cost decrease and COST3 - use of pastures) and the knowledge, education or training the respondents desired to have as concerns certain management practices (HERD1-animal management, HERD2 - animal feed management, HERD3 - milking management and HERD4 - animal replacement). In order to assess the unidimensionality of the resulting factors, a CFA using Lisrel 8.54 was conducted. In this way, it was confirmed that the empirical measures (variables) represented a single concept (nomological validity) and that the factors were homogeneous (convergent validity) (Jöreskog and Sörbom 1993). 
Table 1 Main demographic characteristics of the sampling farmers

\begin{tabular}{|c|c|c|}
\hline Years in livestock business & Number of farmers & Percentage $(\%)$ of farmers \\
\hline $1-5$ years (minimum) & 18 & 16.3 \\
\hline $6-10$ & 12 & 10.9 \\
\hline $11-15$ (median) & 18 & 16.3 \\
\hline $16-20$ & 17 & 15.4 \\
\hline More than 20 years (maximum) & 45 & 40.9 \\
\hline Total & 110 & 100 \\
\hline Who works at the farm & Number of farmers & Percentage $(\%)$ of farmers \\
\hline Family members & 67 & 61 \\
\hline Permanent employees & 15 & 13.6 \\
\hline Seasonal workers & 28 & 25.4 \\
\hline Total & 110 & 100 \\
\hline Employment besides livestock farming & Number of farmers & Percentage $(\%)$ of farmers \\
\hline Yes & 62 & 56.4 \\
\hline No & 58 & 43.6 \\
\hline Total & 110 & 100 \\
\hline Herd size (number of animals) & Number of farmers & Percentage $(\%)$ of farmers \\
\hline Less than 50 animals (minimum) & 14 & 12.7 \\
\hline $50-99$ & 21 & 19.1 \\
\hline $100-149$ & 17 & 15.4 \\
\hline $150-199$ & 12 & 10.9 \\
\hline $200-249$ & 14 & 12.7 \\
\hline $250-299$ & 8 & 7.2 \\
\hline $300-349$ & 6 & 5.4 \\
\hline More than 350 animals (maximum) & 18 & 16.3 \\
\hline Total & 110 & 100 \\
\hline Milk production (tonnes) & Number of farmers & Percentage $(\%)$ of farmers \\
\hline Less than 10 tonnes (minimum) & 44 & 40 \\
\hline $11-20$ & 23 & 20.2 \\
\hline 21-30 (median) & 16 & 14.5 \\
\hline $31-40$ & 6 & 5.4 \\
\hline More than 41 tonnes (maximum) & 21 & 19.1 \\
\hline Total & 110 & 100 \\
\hline Breeding animals & Number of farmers & Percentage $(\%)$ of farmers \\
\hline Sheep & 48 & 45.7 \\
\hline Goats & 39 & 35.4 \\
\hline Annual income & Number of farmers & Percentage $(\%)$ of farmers \\
\hline Less than 5,000 euros & 21 & 19.09 \\
\hline $5,001-10,000$ euros & 22 & 20 \\
\hline $10,001-20,000$ euros & 32 & 29.09 \\
\hline $20,001-30,000$ euros & 19 & 17.27 \\
\hline More than 30,000 euros & 16 & 14.54 \\
\hline Percentage (\%) of income from non-livestock activities & Number of farmers & Percentage (\%) of farmers \\
\hline $1-20 \%$ & 38 & 34.5 \\
\hline $21-40 \%$ & 22 & 20 \\
\hline $41-60 \%$ & 25 & 22.7 \\
\hline $61-80 \%$ & 17 & 15.45 \\
\hline $81-100 \%$ & 8 & 7.27 \\
\hline Total & 110 & 100 \\
\hline
\end{tabular}


The second step of the analysis was to employ cluster analysis so as to identify similar groups of small ruminant farmers based on the previously extracted factors. The particular methodology involved a combination of the hierarchical and the $K$-means clustering methods. First, the factors were subjected to hierarchical cluster analysis (Ward's method, squared Euclidean distance) to determine the range of cluster solutions and to estimate their centroids. After the examination of the revealed agglomeration coefficients, it was revealed that the optimal number of clusters was three (Hair et al. 2010, p. 545). Subsequently, the centroids for the three-cluster solution were used in $K$-means cluster analysis to validate the initial grouping of farmers.

In the third step, the validation of cluster analysis results was assessed via discriminant analysis. The specific analysis is used to separate the variance of linear combined variables of two or more groups from the single within-group variance. Particularly, the maximization procedure intends to "spread apart" the group means while simultaneously compressing the differences between the individual variable values and their respective group means (Cramer 2003, p. 203). The stepwise method was adopted by employing an $F$ value of 1.00 (default value) for entry.

Subsequently, the profile of the clusters was developed on the grounds of a set of categorical variables that were introduced in the questionnaire. The variables involved the age of the farmer, the years of farm operation, the herd size, the annual income, the farmer's membership to a cooperative and the methods of animal feeding. Subsequently, the categorical variables along with the three-cluster identity were subjected to one-way ANOVA analysis to identify possible differences between the clusters (all variables demonstrated significant differences) and to cross-tabulation analysis to complete the cluster profile.

\section{Results and discussion}

The aim of the present study was to classify small ruminant farmers (sheep and goat) based on how they have reacted against the economic crisis and, particularly, which management practices have been implemented to lessen the negative effects of the economic recession and the degree of knowledge, education or training they desired to receive for improved farm management. Accordingly, we conducted a quantitative survey with a structured questionnaire on a sample of 110 sheep and goat farmers in the region of Anatoliki Makedonia and Thraki. The data obtained were analysed through a combination of multivariate techniques, including exploratory factor analysis, confirmatory factor analysis (first methodological step), cluster analysis (second methodological step) and finally, in a third step, discriminant analysis.
3.1 Results from factor and confirmatory factor analysis

As regards factor analysis, ten factors were identified. It is clear that the majority of factor loadings were well above 0.7 , whereas all factors had alpha values exceeding 0.55 , which is considered as an "acceptable value" for internal consistency reliability (McRae et al. 2010). Regarding the results of confirmatory factor analysis, all goodness-of-fit indices (confirmatory fit index, CFI, greater than 0.90 and root mean square error of approximation, RMSEA, less than 0.08 ), were consistently within the acceptable limits demonstrating a good fit of the data. Table 2 illustrates the results from the aforementioned analyses.

\subsection{Results from cluster and discriminant analysis}

Subsequently, the factors were subjected to cluster analysis to classify the farmers. As mentioned above, the threecluster solution exhibited the simplest interpretation and showed the highest number of statistically significant differences among the clusters (Table 3). The three demarcated clusters (cluster 1, $n=52$; cluster 2, $n=42$; cluster 3, $n=16$ ) were clearly distinct with regard to the management practices that small ruminant farmers implement and the knowledge or training they wished to obtain regarding an array of herd management tactics.

The nominal cluster identity variable for the three-cluster solution was saved for subsequent validation and profile analysis. The variables that entered the model were proved as significant discriminators, since the chi-square statistic $\left(X^{2}=98.238\right)$ pointed to highly significant discriminant functions, and the small and significant value of Wilk's lambda (value $=0.373$ at $p<0.001$ ) represented a high level of discriminating power. The predictive validity of the discriminating functions was assessed by means of the hit ratio (percentage correctly classified), revealing how well the discriminant function classified the farmers. Indeed, the classification matrix for the observations indicated that $97.5 \%$ of the small ruminant farmers were correctly and validly classified (Table 4).

\subsection{Profile description of the farmers' clusters and discussion}

The active entrepreneurs This cluster consists of almost half of the farmers in the sample $(47.2 \%$ of the sample -52 farmers), mainly men and with an interesting percentage of $16 \%$ being women. They received mostly primary and secondary education, they have operated their farms for more than 20 years possessing more than 200 animals on average and almost half of them (51.9\%) have more than 20,000 euros of annual income. The majority belongs to a local cooperative, preferring mostly to feed their animals 
Table 2 Factor analysis results-confirmatory factor analysis results: standardized loadings (maximum likelihood estimations) and measured reliabilities

\begin{tabular}{|c|c|c|c|c|c|c|}
\hline Code & Name of factor - items tapping each factor ${ }^{a}$ & $\begin{array}{l}\text { Factor } \\
\text { oading }\end{array}$ & Eigenvalue & $\begin{array}{l}\text { Variance } \\
(\%)\end{array}$ & Goodness-of-fit measures & $\begin{array}{l}\text { Standardized } \\
\text { path coefficients }\end{array}$ \\
\hline \multirow[t]{3}{*}{ CR1 } & Crisis and production cost $(\alpha=0.662)$ & & 1.342 & 33.54 & $\begin{array}{c}X^{2}, 2.25 ; d f, 1 ; p \text { value, } \\
0.013 ; \mathrm{CFI}^{\mathrm{e}}, 0.98 \\
\text { RMSEA }^{\mathrm{f}}, 0.073\end{array}$ & \\
\hline & Cost of production & 0.82 & & & & 0.68 \\
\hline & Animal feed cost & 0.81 & & & & $1^{\mathrm{c}}$ \\
\hline \multirow[t]{3}{*}{ CR2 } & Crisis and marketing cost $(\alpha=0.596)$ & & 1.198 & 63.5 & & \\
\hline & Product demand & 0.91 & & & & $1^{\mathrm{c}}$ \\
\hline & Farm financing & 0.76 & & & & 0.45 \\
\hline \multirow[t]{8}{*}{ MP1 } & Employment cost decrease $(\alpha=0.983)$ & & $6.209^{\mathrm{d}}$ & 100 & $\begin{array}{l}X^{2}, 10.12 ; d f, 9 ; p \text { value, } \\
\text { 0.034; CFI, } 1.00 \\
\text { RMSEA, } 0.024\end{array}$ & \\
\hline & Reduce in wages & $1.00^{\mathrm{d}}$ & & & & 0.71 \\
\hline & Redistribution of working hours (more hours) & 1.00 & & & & 0.54 \\
\hline & Conversion to family business & 1.00 & & & & 0.50 \\
\hline & More personnel specialization & 1.00 & & & & 0.92 \\
\hline & Hiring seasonal employees & 1.00 & & & & $1^{\mathrm{c}}$ \\
\hline & Hiring foreign employees & 1.00 & & & & 0.78 \\
\hline & Reduce workers outside the family & 1.00 & & & & \\
\hline \multirow[t]{7}{*}{ COST1 } & Input cost decrease $(\alpha=0.993)$ & & 4.769 & 39.75 & $\begin{array}{l}X^{2}, 67.7 ; d f, 34 ; p \text { value, } \\
\text { 0.00052; CFI, 0.96; } \\
\text { RMSEA, } 0.068\end{array}$ & \\
\hline & Reduce the use of fertilizers & 0.98 & & & & $1^{\mathrm{c}}$ \\
\hline & Less use of petrol & 0.86 & & & & 0.95 \\
\hline & Increase in animal feed storage & 0.86 & & & & 0.78 \\
\hline & Product processing & 0.85 & & & & 0.63 \\
\hline & Less use of expendables & 0.70 & & & & 0.61 \\
\hline & Import animal feed from other countries & 0.70 & & & & 0.42 \\
\hline \multirow[t]{6}{*}{ COST2 } & Feed cost decrease $(\alpha=0.882)$ & & 4.623 & 38.52 & & \\
\hline & Less animal feed & 0.97 & & & & $1^{\mathrm{c}}$ \\
\hline & Decrease in animal capital & 0.97 & & & & 0.72 \\
\hline & Reduce expensive animal feed & 0.97 & & & & 0.56 \\
\hline & Decrease in the use of feed supplements & 0.66 & & & & 0.49 \\
\hline & Organic livestock & 0.60 & & & & 0.45 \\
\hline \multirow[t]{2}{*}{ COST3 } & Use of pastures & & 1.433 & 11.94 & & \\
\hline & Using pastures for grazing & 0.88 & & & & $1^{\mathrm{c}}$ \\
\hline \multirow[t]{6}{*}{ HERD1 } & Animal management $(\alpha=0.815)$ & & 2.479 & 22.53 & $\begin{array}{l}X^{2}, 73.11 ; d f, 34 ; p \text { value, } \\
0.00011 ; \text { CFI, } 0.90 \\
\text { RMSEA, } 0.045\end{array}$ & \\
\hline & Improve the hygiene conditions & 0.84 & & & & $1^{\mathrm{c}}$ \\
\hline & Management of pregnant animals & 0.82 & & & & 0.78 \\
\hline & Management of replacement animals & 0.64 & & & & 0.58 \\
\hline & Animal comfort, animal housing & 0.61 & & & & 0.51 \\
\hline & Use of improved animals & 0.56 & & & & 0.56 \\
\hline \multirow[t]{4}{*}{ HERD2 } & Animal feed management $(\alpha=0.729)$ & & 2.228 & 20.26 & & \\
\hline & Prepare quality feed & 0.93 & & & & $1^{\mathrm{c}}$ \\
\hline & Use of economical and balanced rations & 0.87 & & & & 0.86 \\
\hline & Practices for organic livestock production & 0.76 & & & & 0.82 \\
\hline \multirow[t]{3}{*}{ HERD3 } & Milking management $(\alpha=0.677)$ & & 1.592 & 14.48 & & \\
\hline & Managing animals during milking production & 0.80 & & & & $1^{\mathrm{c}}$ \\
\hline & Electronic milking systems and management & 0.79 & & & & 0.96 \\
\hline
\end{tabular}


Table 2 (continued)

\begin{tabular}{llllll}
\hline Code & Name of factor-items tapping each factor ${ }^{\mathrm{a}}$ & $\begin{array}{l}\text { Factor } \\
\text { oading }\end{array}$ & Eigenvalue & $\begin{array}{l}\text { Variance } \\
(\%)\end{array}$ & $\begin{array}{r}\text { Goodness-of-fit measures } \\
\text { path coefficients }\end{array}$ \\
\hline HERD4 & $\begin{array}{l}\text { Animal replacement } \\
\text { Procedures of animals replacement in the farm }\end{array}$ & 1.00 & 1.073 & 9.75 & $1^{\mathrm{c}}$ \\
\hline
\end{tabular}

${ }^{a}$ All measurement scales are 5-point Likert-type scales anchored (1) completely disagree to (5) completely agree

${ }^{\mathrm{b}}$ Standardized first-order loadings

${ }^{\mathrm{c}}$ Item fixed to set the scale/not tested for significance

${ }^{\mathrm{d}}$ Only one factor was extracted (solution not rotated)

${ }^{\mathrm{e}} \mathrm{CFI}$, acceptable values greater than 0.90

${ }^{\mathrm{f}} \mathrm{RMSEA}$, acceptable values less than 0.08

with animal food. Generally, the economic recession did not have a major effect on their performance, especially in their production cost and feed cost. Nevertheless, the active entrepreneurs appear to have adopted an array of tactics to further tackle any negative effects of the economic crisis. Particularly, their practices focused mainly on further minimizing the employment cost through work redistribution, hiring of seasonal workers and employment specialization. However, they did not follow any tactics for reducing input cost, whereas they were more oriented in using the pastures for animal grazing. As regards the level of knowledge, education or training they desire to obtain regarding herd management practices, the small ruminant farmers in this cluster deem important the practices of housing and hygiene as well as methods for better handling of pregnant animals and the animals for replacement. In addition, they would like to be educated or trained in methods for economical and balanced animal feeding, use of more efficient and electronic milking systems along with keeping their herd in a high rate of replacement.
The complacent farmers Forty-two small ruminant farmers ( $38.1 \%$ of the sample) belong to this cluster, incorporating male farmers of primary education, non-members of a specific cooperative, being more than 16 years in the livestock business and having an average income that ranges between 10,000 and 20,000 euros per year (almost $60 \%$ of them); intriguingly, $16 \%$ of them are new farmers. The majority in this cluster has an average herd size of 200 animals that are mainly fed indoor with little grazing. This cluster seems not to have been affected significantly by the economic crisis as they performed specific management practices in a moderate manner, whereas they do not have a strong interest to be trained or educated for optimum farm management. More importantly, the complacent farmers chose to follow the path of reducing the feeding cost including less use of animal feedstuff, reducing the expensive food and lessening the use of feed supplements. Nevertheless, using the pastures for grazing is not perceived as a priority practice to follow.

Table $3 \mathrm{~K}$-means cluster analysis results (three-cluster solution). Mean scores of each factor for every cluster of small ruminant farmers

Final cluster centres

\begin{tabular}{|c|c|c|c|c|c|c|c|c|}
\hline \multicolumn{7}{|l|}{ Clusters } & \multirow[t]{2}{*}{$F$ statistic } & \multirow[t]{2}{*}{ Significance } \\
\hline Factors & Code & $1(n=52)$ & $2(n=42)$ & $3(n=16)$ & $\begin{array}{l}\text { Cluster mean } \\
\text { square }\end{array}$ & $\begin{array}{l}\text { Error mean } \\
\text { square }\end{array}$ & & \\
\hline Crisis and production cost & CR1 & 3.62 & 4.14 & 4.47 & 10.670 & 0.618 & 20.085 & 0.042 \\
\hline Crisis and marketing cost & CR2 & 2.27 & 2.29 & 2.43 & 0.159 & 0.333 & 0.477 & 0.622 \\
\hline Employment cost decrease & MP1 & 3.32 & 2.94 & 3.13 & 21.862 & 0.482 & 18.787 & 0.073 \\
\hline Input cost decrease & COST1 & 2.99 & 3.26 & 2.21 & 0.889 & 0.546 & 1.629 & 0.201 \\
\hline Feed cost decrease & COST2 & 2.83 & 2.93 & 2.17 & 3.300 & 0.471 & 7.008 & 0.001 \\
\hline Use of pastures & COST3 & 4.50 & 2.45 & 3.40 & 50.924 & 0.627 & 81.160 & 0.000 \\
\hline Animal management & HERD1 & 4.27 & 3.72 & 2.15 & 8.364 & 0.301 & 27.769 & 0.000 \\
\hline Animal feed management & HERD2 & 4.18 & 3.43 & 2.67 & 15.250 & 0.471 & 32.376 & 0.000 \\
\hline Milking management & HERD3 & 4.11 & 3.80 & 2.57 & 6.339 & 0.799 & 7.936 & 0.001 \\
\hline Animal replacement & HERD4 & 3.78 & 3.43 & 2.13 & 15.651 & 0.805 & 19.447 & 0.000 \\
\hline
\end{tabular}

${ }^{*} p$ value $<0.01$, statistically significant 
Table 4 Classification results for the three clusters of small ruminant farmers $(97.5 \%$ of the originally grouped small ruminant farmers were correctly classified.)

\begin{tabular}{|c|c|c|c|c|c|}
\hline \multicolumn{6}{|c|}{ Classification results } \\
\hline & \multirow[t]{2}{*}{$\begin{array}{l}\text { Cluster number } \\
\text { of case }\end{array}$} & \multicolumn{3}{|c|}{$\begin{array}{l}\text { Predicted group } \\
\text { membership }\end{array}$} & \multirow[t]{2}{*}{ Total } \\
\hline & & 1 & 2 & 3 & \\
\hline \multirow[t]{3}{*}{ Count } & 1 & 52 & 0 & 0 & 52 \\
\hline & 2 & 1 & 39 & 0 & 40 \\
\hline & 3 & 0 & 0 & 16 & 16 \\
\hline \multirow[t]{3}{*}{ Percentage $\%$} & 1 & 100.0 & 0.0 & 0.0 & 100.0 \\
\hline & 2 & 2.5 & 97.5 & 0.0 & 100.0 \\
\hline & 3 & 0.0 & 0.0 & 100.0 & 100.0 \\
\hline
\end{tabular}

The non-active farmers Unlike the two other clusters, small ruminant farmers in this cluster exhibit totally different characteristics. They comprise low-income males (less than 10,000 per year for the $75 \%$ of them) that received primary and (intriguingly) secondary education (20\%), adding up to 16 farmers ( $14.7 \%$ of the sample). They have operated for more than 20 years in the livestock sector, the majority $(60 \%)$ is not a member of a particular cooperative and they have an average herd size between 150 and 250 animals with a preference to use the pastures for grazing. Specifically, the herd mainly comprise sheep $(67 \%)$ and to a lesser extent goats (26\%) and cows $(6 \%)$. This cluster argued that the impacts of the economic crisis to their farms were severe, especially on the cost of production and animal feedstuff. Nevertheless, interestingly, these farmers did not follow any particular tactics to lessen the adverse effects of the recession on the operation cost. In general, the majority of management practices followed exhibit a negative sign, demonstrating a rather passive attitude towards actions that need to be taken in the struggle against the economic downturn. More obvious results indicate their denial to receive education or training as concerns the animal feed management, the adaptation of new technologies in the milking procedure and the procedures for herd replacement.

The results accrued demonstrate that the majority of farmers - the active entrepreneurs and the complacent farmers-have adopted a more dynamic (or intermediate respectively) managerial behaviour for reducing the adverse effects of the economic crisis (Fig. 3).

These strategies, mainly cost effective, involved the decrease in employment cost and redistribution of employment in the farm, along with a reduction in feeding cost. The findings corroborate those reported in the extant literature (Sintori et al. 2009; Berbel and Rodriguez-Ocana 1998). The non-active farmers exhibit a more static attitude facing the economic crisis, as few steps have been taken to lessen the negative (and significant) impacts on their farms. The main practice followed was the animals' use of the pastures. This behaviour may be attributed to the fact that the cluster primarily refers to smallscale livestock farms with a less intensive character, which have reached a level of self-sufficiency, or not having the bargaining power to solve inefficiencies within their farms.

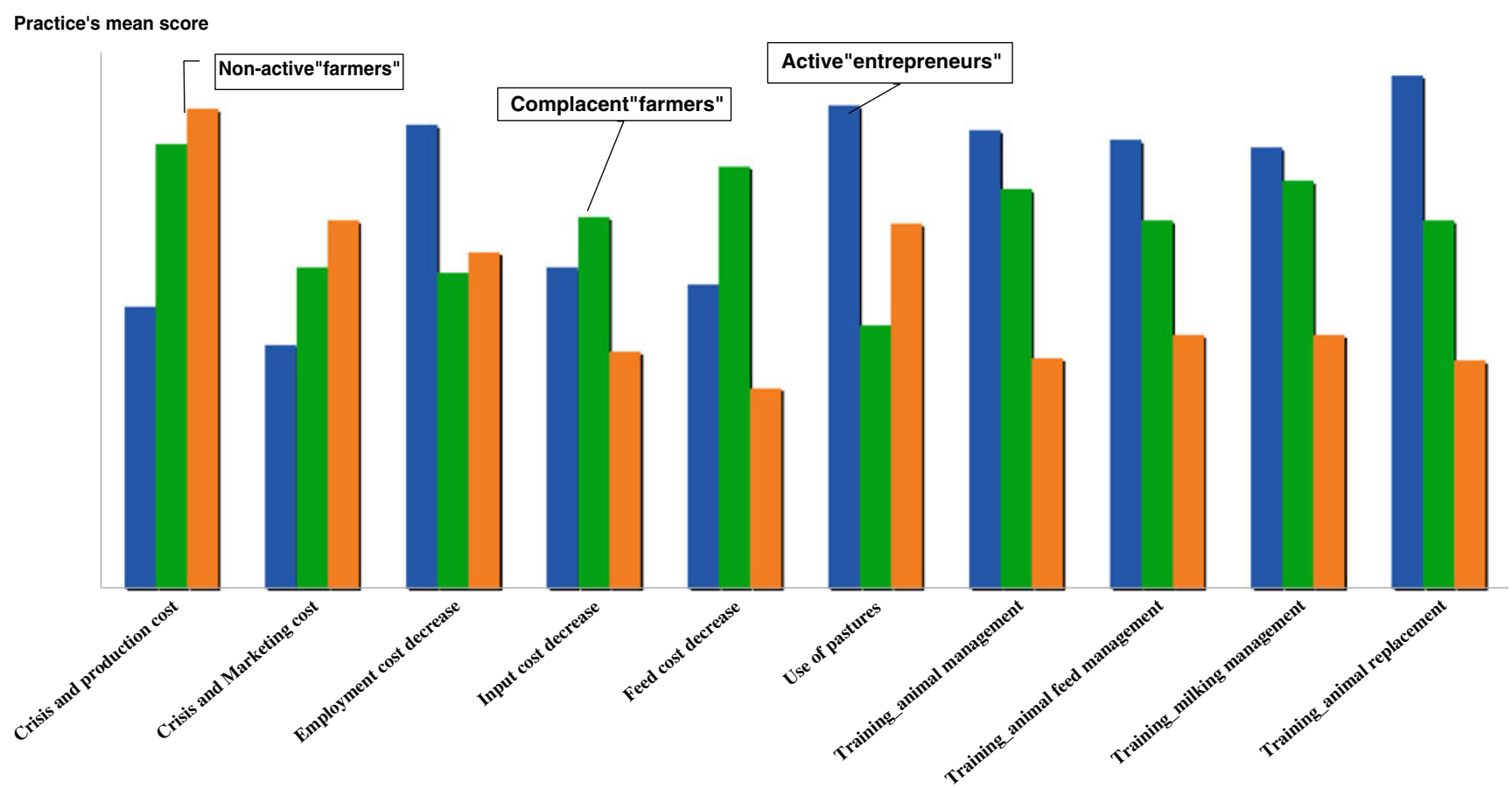

Fig. 3 Small ruminant farmers' mean scores to each one of the implemented management practices and the level of education or training farmers (in each cluster) wished to obtain. Mean score values range from 2.13 to 4.50 . The higher the score, the more likely a specific strategy was adopted 
The results from the preceding analyses provide the grounds that there is no single "best practice" that guarantees livestock farm survival, or success, under recession conditions. The current evidence offers no consensus as to whether retrenchment, investment or ambidextrous tactics are more likely to bring about survival or success. However, the results point to directions where policy action should be undertaken, since in order to provide timely assistance, agribusiness state authorities need to comprehend which group of small ruminant farmers requires urgent assistance. The three demarcated groups, with such different profiles in terms of management behaviour, urge for a multidimensional policy intervention to better tackle economic vulnerabilities. These farmers, strongly associated with a remote and less favoured area, relied heavily on European subsidies that constituted a significant part of their earnings (Galanopoulos et al. 2012; de Rancourt et al. 2006). Therefore, their concern was more on the increase in the herd size so as to take advantage of subsidies and other compensations, irrespective of animal productivity, along with improving labour efficiency rather than making capital investments. This has created a rather extensive sector with a very low invested capital, whereas the more intensive and modern farms have appeared recently, especially in the lowlands (Hellenic Ministry of Rural Development and Food 2011)

Accordingly, policy orientation in Greece was directed primarily to livestock farms that can be better off from programmes that effectively assist them to make use of new management practices. Nevertheless, programmes that successfully address small ruminant farmers' inquiries should be planned as well; otherwise, policy implementation runs the risk of making larger farms better off and smaller farms worse off. Policy intervention should focus on the establishment of livestock services programmes (where needed) or the enhancement of existing ones, bearing in mind employing training programmes to assist small ruminant farmers understand popularly used farm survival tactics. The organization of farmers' cooperatives is also deemed important to improve their bargaining power achieving better market prices and reducing input costs. The study's findings demonstrate that the majority of the sampling farmers have already followed various forms of micro-level management adjustments. Still, the improvement in farming efficiency lies on the convergence of individual initiatives and effective and timely government support.

\section{Conclusion}

The present study classified small ruminant farmers in a remote Greek region on the basis of the adopted management practices to face the economic crisis. The active entrepreneurs ( $47.2 \%$ of the sample) responded to the economic crisis via a more dynamic behaviour characterized by costeffective practices in employment and feeding stuff. The reaction of the complacent farmers (38.1\% of the sample) was neutral and mainly focused on reducing the feeding inputs, whereas the non-active farmers $(14.7 \%$ of the sample) adopted a passive behaviour without implementing any particular strategy. All the groups highlighted the need for better education and training regarding aspects of economical and balanced feeding, the use of new technologies in the farm and procedures for herd replacement and health. The innovative aspect of the study is that it comprises a first attempt to measure response to an ongoing economic crisis that has changed normal behaviour and expectations, and increased risk and uncertainty. In this sense, it assesses the management practices that small ruminant farmers, in a remote and less favourite Greek region, implement in order to effectively respond to the ongoing economic downturn and enhance their viability. However, the study was confined to a single, small ruminant farmers' context in a specific region, and generalization of the findings outside of this context should be done cautiously. Managerial decision making on behalf of the farmers may have been influenced given the fact that the sampling farmers were breeding also other animals besides sheep and goats. Still, this study may provide an opportunity for further research regarding how different kinds of livestock farmers implemented management practices in order to persist during the economic recession.

\section{References}

Berbel J, Rodriguez-Ocana A (1998) An MCDM approach to production analysis: an application to irrigated farms in Southern Spain. Eur J Oper Res 107(1):108-118

Burns A, Burns R (2008) Basic marketing research (second edition). Pearson Education, New Jersey, p 245. ISBN 978-0-13-205958-9

Cramer D (2003) Advanced quantitative data analysis. Open University Press McGraw-Hill, Berkshire, ISBN 0335200591 (pb)

Darnhofer I, Bellon S, Dedieu B, Milestad R (2010) Adaptiveness to enhance the sustainability of farming systems. a review. Agron Sustain Dev 30:67-81. doi:10.1051/agro/2009053

de Rancourt M, Fois N, Lavin MP, Tchakerian E, Vallerand F (2006) Mediterranean sheep and goats production: an uncertain future. Small Ruminant Res 62:167-179. doi:10.1016/ j.smallrumres.2005.08.012

Dedieu B (2009) Qualification of the adaptive capacities of livestock farming systems. Rev Bras Zoot 38:397-404. doi:10.1590/S151635982009001300039

Freedman D, Pisani R, Purves R (2007) Statistics, 4th edn. WW, Norton \& Company, New York, ISBN-10: 0393929728

Galanopoulos K, Abas Z, Laga V, Hatziminaoglou I, Boyazoglou J (2012) The technical efficiency of transhumance sheep and goat farms and the effect of EU subsidies: do small farms benefit more than large farms? Small Ruminant Res 100:1-7. doi:10.1016/ j.smallrumres.2011.05.008

Galanopoulos K, Aggelopoulos S, Kamenidou I, Mattas K (2006) Assessing the effects of managerial and production practices on the efficiency of commercial pig farming. Agr Syst 88:125-141. doi:10.1016/j.agsy.2005.03.002 
Hellenic Ministry of Rural Development and Food (2011) Study on the Greek livestock sector (in Greek). Animal Production, Athens, 2011. http://www.minagric.gr/greek/data/18853.pdf. Accessed 21 August 2012

Hair J, Anderson RE, Tatham LR, Black CW (2010) Multivariate data analysis, 7th edn. Pearson Prentice Hall, New Jersey

Hardaker JB, Huirne RBM, Anderson JR (1998) Coping with risk in agriculture, 1st edn. CAB Publishing, Wallingford

Ho GTS, Choy SH, Lam CHY (2010) An examination of strategies under the financial tsunami. Int Manage Data Syst 110(9):13191336. doi: $10.1108 / 02635571011087419$

Jöreskog KG, Sörbom D (1993) Scientific Software International. LISREL 8. IL7, Chicago

Kitching J, Blackburn R, Smallbone D, Dixon S (2009) Business strategies and performance during difficult economic conditions, for the department of business innovation and skills. (Project Report) London, U.K.: Department for business innovation and skills (BIS). URN 09/1031. http://www. berr.gov.uk/files/file51879.doc. Accessed 20 December 2012

Koo R (2009) The holy grail of macroeconomics: lessons from Japan's great recession. Wiley, Singapore

McNally S (2001) Farm diversification in England and Wales-what can we learn from the farm business survey? J Rural Stud 17:247257. doi:10.1016/S0743-0167(00)00050-4

McRae RR, Kurtz JE, Yamagata S, Terracciano A (2010) Internal consistency, retest reliability, and their implications for personality scale validity. Pers Sco Psychol Rev 15(1):28-50. doi:10.1177/ 1088868310366253

National Statistical Service of Greece (2012) Agriculture and livestock census. [Online]. http://www.statistics.gr. Accessed 20 December 2012
Nozieres MO, Moulin CH, Dedieu B (2011) The herd, a source of flexibility for livestock systems faced with uncertainties? Animal 5:1442-1457. doi:10.1017/S1751731111000486

Pearce JII, Michael S (2006) Strategies to prevent economic recessions from causing business failure. Bus Horizons 49:201-209. doi:10.1016/j.bushor.2005.08.008

Posner JL, Frank GG, Nordlund KV, Schuler RT (2008) A constant goal, changing tactics: the Krusenbaum dairy farm 1996-2005. Renew Agr Food Syst 24(1):8-18. doi:10.1017/ S1742170508002378

Rahelizatovo NC, Gillespie JM (2004) The adoption of bestmanagement practices by Louisiana dairy producers. J Agr Appl Econ 36(1):229-240

Reidsma P, Ewert F, Lansink AO, Leemans R (2010) Adaptation to climate change and climate variability in European agriculture: the importance of farm level responses. Eur J Agron 32:91-102. doi:10.1016/j.eja.2009.06.003

Schumpeter JA (1976) Capitalism, socialism and democracy. Harper, New York, Originally published in 1943

Sintori A, Rozakis S, Tsiboukas K (2009) Multiple goals in farmers' decision making: the case of sheep farming in western Greece. Proceedings of the 83rd Annual Conference of the Agricultural Economics Society Dublin Ireland. http://purl.umn.edu/51075. Accessed 20 December 2012

Smit B, Skinner M (2002) Adaptation options in agriculture to climate change: a typology. Mitig Adapt Strat Glob Change 7:85-114. doi:10.1023/A: 1015862228270

Zehir C (2005) The activation level of crises and the change of strategic targets of enterprises in Turkey during the depression era. J Am Acad Bus 5:293-299

Windle J, Rolfe J (2005) Diversification choices in agriculture: a choice modelling case study of sugarcane growers. Aus J Agr Res Econ 49:63-74. doi:10.1111/j.1467-8489.2005.00279.x 